\title{
An ergonomic study on the navigation structure and information units of websites with multimedia content. A case study of the Xbox 360 promotional website ${ }^{1}$
}

\author{
Eduardo Ariel ${ }^{\mathrm{a}}$ and Anamaria de Moraes ${ }^{\mathrm{b}}$ \\ ${ }^{a}$ School of Advertising and Marketing - ESPM, Rio de Janeiro - Brazil \\ ${ }^{b}$ Pontifical Catholic University of Rio de Janeiro, RJ - Brazil
}

\begin{abstract}
This paper presents an ergonomic study on the navigation structures and information units of entertainment sites with multimedia content. This research is a case study on the XBOX 360 promotional website. It analyzes the presentation of the content on a grid that simulates the spatial displacement of the screen's elements and evaluates the interaction that the page allows for, from the users' point of view.
\end{abstract}

Keywords: interaction design, human-computer interaction, use experience, usability and spatial navigation

\section{Introduction}

The research about Human-Computer Interaction, in the context of studies about the interface usability of Web products, focuses on navigation structure and spatial interaction of websites with multimedia content for the entertainment segment. It analyzes the XBOX 360 promotional website case study and user interaction with this product.

\section{Research outline}

The research problem is related to the event of the designers creating a lively atmosphere that seeks to enhance the sensory focus of the multimedia experience, disregarding the user-centered project and the main usability recommendations.

The first hypothesis of the study is that the lack of feedback when selecting an item of lively content and the difficulty to understand the navigation controls are barriers that make it difficult for users to interact with the spatial navigation structure of the XBOX 360 website. The second hypothesis analyzes how the aesthetics and graphic innovation of the in- terface minimize the users' perception of the usability problems encountered during interaction.

The research aims to offer recommendations to help minimize interaction problems, attributable to the presentation of this information in a spatial navigation structure.

\section{Xbox 360 website}

The role of the XBOX 360 website is to encourage and enable users to test Microsoft's product for the home entertainment market - third generation games.

An off-line version of the website was made for this research, containing all of the published files. Typographical style and layout Fine tuning

\footnotetext{
${ }^{1}$ Corresponding author.
} 


\section{Methods and techniques}

Below are the methods, techniques and procedures that were carried out in the research.

The "Creating Personas" questionnaire was responsible for mapping the user profile through the material object (the XBOX 360 site). This information referring to the persona was used as a base for creating the present scenarios of the usability tests.

The QUIS, user satisfaction questionnaire, was used in an early stage to assist in mapping the areas and items on the page that could bring dissatisfaction to the participants of the study. These respondents were selected based on data obtained by the "Personas" questionnaire and their answers were fundamental to creating the tasks in the scenario.

The usability test made it possible to observe the difficulties, frustrations, and unexpected behavior shown by users during their interaction with the XBOX 360 website. In this procedure, after performing the last task of the scenario presented, they responded to the "Evaluation of Pleasures" questionnaire to quantify the pleasure of the proposed interaction.

Finally, as the last technique, the QUIS allowed for a quantitative evaluation of the participants' satisfaction with regards to the material object of study, after having done usability tests and responded to the "Evaluation of Pleasures" questionnaire.

\section{Discussion of the results}

The objective of the first QUIS application along with the collaborators of the study is to discover the main problems presented by the XBOX 360 website. The positive evaluations made by respondents were: the organization and quantity of information on the screen, the time to learn how to use the site, the response time for the majority of the operations, using a page when knowing only a few commands. However, the highest score obtained for a result that wasn't negative was $62 \%$.

The usability test revealed that some participants felt visual discomfort and dizziness. Their accounts refer to the rotation and to the depth effect of the elements presented on the screen. Considering this information, it is possible to say that the problems went beyond those of nonconformity of usability and interaction.

The analysis of the research results that considers the usability tests and user satisfaction questionnaires
(QUIS) shows that despite its initial appeal, the site has several problems. They are described below:

The page presented navigation problems, as it was evaluated by users as confusing and not very direct. Moreover, the difficulty for users to undo actions and to view the controls made the navigation progression complex. Furthermore, learning about advanced resources was evaluated as complicated.

Content access was not an easy task due to the passive position imposed by the animation of the page and the unusual double click used to open the content. Moreover, the lack of descriptions for their icons and buttons may, in part, explain these problems. Because of this, users were unable to understand the meaning of the floating objects on the screen and that they serve as links to the content.

The sounds were evaluated as irritating and did not help during the interaction.

Finally, the "Evaluation of Pleasures" questionnaire given right after the last task of the usability test showed the following results: four of the ten graphics registered positive figures of less than $50 \%$, another four were higher than $58 \%$ and only two had a negative score. The best scores were for the topics attraction (77\%) and fun (68\%). The worse evaluation $(32 \%)$ related to the issue "how the page would be if the user does not have prior knowledge of it". These results may mean that the "Evaluation of Pleasures" was good, but usability issues recorded may explain why the rating was not even better.

\section{Final considerations}

Thus we can consider that the first hypothesis was confirmed. To facilitate understanding, we should recall the difficulties with the previous items cited in this article. The second hypothesis was also confirmed as the first impression of the page was so positive that the users never stopped interacting and the results of the evaluation of pleasures questionnaire indicate an appreciation of the site. Thus, one can consider that if the aesthetics and emotional benefits were not so pleasurable and rewarding, it is likely that the usability problems would have been of a greater dimension. And, therefore, users may have disrupted their interaction and use of the site.

It is important to state that the objective of the research was achieved, as the tests brought recommendations that arose from the observations. Among them are: 
- Use descriptions on all of the icons;

- Provide contextualized information that uses language easily understood by users for each one of their actions;

- Allow the user to have control in all of his/her actions;

- Include auxiliary navigation resources;

These considerations cannot be generalized because the average age of collaborators is very controlled and all of them are from areas linked to interface development.

\section{References}

[1] [Carroll \& Rosson02] Carroll, J. M., Rosson, M. B. Usability Engineering: Scenario - Based Development of Human Computer Interaction. San Francisco: Morgan Kaufmann Publishers Inc., 422 p., 2002.

[2] [Cooper99] Cooper, A. The inmates are running the asylum. Why high-tech products drive us crazy and how to restore the sanity. Indianapolis: Sams - Macmillan Computer Publishing, 1999. p. 261.

[3] [Dumas \& Redish99] Dumas, J. S.; Redish, J. C. A Practical Guide to Usability Testing. United Kingdom: Intellect Books, p. 22-416, 1999.

[4] [Jordan02] Jordan, P.W. How to Make Brilliant Stuff That People Love and Make Big Money Out of It. England: John Wiley \& Sons Inc., 126 p., 2002.

[5] [Jordan00] J Jordan, P. W. Designing Pleasurable Products. London: Taylor \& Francis Group Books Ltd., 216 p., 2000.

[6] [Kuniavsky03] Kuniavsky, M. Observing the user experience: a practitioner's guide to user research. San Francisco: Morgan Kaufmann Publishers Inc., 2003.

[7] [Motta99] Motta, P. C. Pesquisando a satisfação do consumidor. Rio de Janeiro: Imprinta Express Gráfica e Editora Ltda., 155 p., 1999

[8] [Moraes92] Moraes, A. In: Diagnóstico Ergonômico do Processo Comunicacional do Sistema Homem-Máquina de Transcrição de Dados: Posto de Trabalho do Digitador em Terminais Informatizados de Entrada de Dados. Rio de Janeiro, 1992. p. 371-376. Thesis (Doctorate in Communications) - Universidade Federal do Rio de Janeiro UFRJ.

[9] [Norman06] Norman, K. L. Questionnaire for User Interaction Satisfaction - University of Maryland (Norman, 1989). Available at: http://www.lap.umd.edu/QUIS/index.html. Last accessed: 18/07/06.

[10] [Preece, Rogers \& Sharp02] Preece, J., Rogers, Y. \& SHARP $H$. Interaction design: beyond human-computer interaction. New York: John Wiley \& Sons, Inc., 519p., 2002.

[11] [Scapin \& Bastien97] Scapin, D. L., Bastien, J. M. C. Ergonomic criteria for evaluating the ergonomic quality of interactive systems. In: Behaviour \& information technology. London, Taylor \& Francis, v.16, n 4/5, July/ October 1997. Pp 220-230. 